\title{
Valid and reliable assessment of wellness among adolescents: Do you know what you're measuring?
}

\author{
Jerome N. Rachele · Tracy L. Washington · Thomas F. Cuddihy \\ Faisal A. Barwais · Steven M. McPhail
}

\begin{abstract}
Measuring wellness among adolescents is an emerging trend among professionals and researchers endeavouring to influence youth as they establish lifestyle patterns in this critical period of life. This discussion highlights instruments used to measure adolescents' wellness, and considers the empirical data supporting the validity and reliability of those instruments. In summary, adolescents' wellness is an important indicator of future health and lifestyle habits. There are a number of tools available to measure wellness, each with its own focus, depending on the definition or model from which it was developed. This might cause debate regarding the appropriateness of some instruments for evaluating wellness. The majority of wellness evaluation approaches used with adolescent populations have less than ideal validation. A 'gold standard' definition could lead to the standardisation of a theoretical model against which wellness instruments could be validated. The absence of peer-reviewed studies reporting psychometric testing for wellness evaluation instruments used with adolescents is of concern given their growing popularity and highlights a priority area for future research in this field.
\end{abstract}

Keywords: wellness, adolescent, measurement technique, instrument

\section{Background}

'Wellness' is often considered the endpoint of physical, mental or social interventions. Wellness has been described as a dynamic process maximizing an individual's potential (Dunn, 1977); a way of life orientated toward optimal health and wellbeing in which body, mind, and spirit are integrated by an individual to live more fully within the human and natural community (Myers, Witmer, \& Sweeney, 2000); and a construct reflecting the process of enhancing life quality by integrating and balancing one's physical, mental, and spiritual wellbeing (Harari, Waehler, \& Rogers, 2005). Although the World Health Organization does not intend its definition to be exhaustive or scientific in nature, it defines wellness as

\begin{abstract}
"the optimal state of health of individuals and groups. There are two focal concerns: the realization of the fullest potential of an individual physically, psychologically, socially, spiritually and economically, and the fulfilment of one's role expectations in the family, community, place of worship, workplace and other settings" (Smith, Tang, \& Nutbeam, 2006).
\end{abstract}

To this end, wellness focuses on lifestyle behaviours which contribute toward individuals living to their fullest potential, and is determined not just in terms of its individual dimensions, but as an integrated whole. Wellbeing on the other hand, has been described as the balancepoint between an individual's resource pool and the challenges faced, whereby stable 
wellbeing is when individuals have the psychological, social and physical resources they need to meet a particular psychological, social and/or physical challenge (Dodge, Daly, Huyton, \& Sanders, 2012). Wellness also differs from other health-related concepts, such as health, which traditionally focuses on the individual in relation to illness status (Breslow, 1972), and quality of life, which has been defined as individuals' perception of their position in life in the context of the culture and value systems in which they live and in relation to their goals, expectations, standards and concerns (Power et al., 1998). To observe the effect interventions have on wellness, or to observe wellness in a sample cohort at a single time point or change over time, it is important that wellness can be quantified. The advancement of wellness theories, such as early definitions provided by Dunn (1977), towards more advanced theories comprising multiple levels of dimensions and subscales such as the Indivisible Self model of wellness (Myers \& Sweeney, 2004a), has resulted in the development of a variety of instruments for measuring wellness.

One population group for whom measuring wellness is particularly important is adolescents. Behaviours or cognitions performed during this time may set the pattern for long periods of adulthood, as many lifestyle choices are established during adolescence (Craigie, Lake, Kelly, Adamson, \& Mathers, 2011; Hallal, Victora, Azevedo, \& Wells, 2006; Trudeau, Laurencelle, \& Shephard, 2004). Unhealthy habits and lifestyle choices established during adolescence can lead to disability and disease later in life. Therefore, adult mortality and morbidity could be reduced by improving health habits in adolescence. Specific wellness dimensions often reflect specific lifestyle outcomes. For example, lifestyle outcomes including stress, self-esteem, self-worth, nutrition and physical activity are also represented as subscales or dimensions within wellness models (Table 1 below). Measures like the Wellness Evaluation of Lifestyle (WEL) (Myers, Sweeney, and Witmer, 1996) and the Five Factor Wellness Inventory (5F-Wel) (Myers \& Sweeney, 1999) have been used in many recent empirical studies (Garrett, 1999; Garrett, Rivera, Dixon \& Myers, 2009; Myers \& Bechtel, 2004; Myers, Willse, \& Villalba, 2011; Rayle \& Myers 2004; Tatar \& Myers, 2010). Scores derived from wellness instruments have been used as both dependent and independent variables to study wellness among youth in relation to diverse psychological constructs and demographic indices; and used across a variety of disciplines including clinical and non-clinical settings. For example: Garrett (1999) used the wellness scores of Native American youth to develop more effective counselling interventions; Myers et al. (2011) explored the extent to which wellness factors are predictive of self-esteem; Tatar and Myers (2010) examined cross-cultural differences in wellness between children in Israel and in the United States; Rayle (2005) examined the impact of mattering on adolescent wellness; Choate and Smith (2003) infused a wellness model into the curriculum design of a first-year college course, as a framework to address student needs; Watson and Lemon (2011) compared the wellness responses of adolescents receiving counselling services at a community mental health centre with a norm group; and Smith-Adcock, Webster, Leonard, and Walker (2008) examined a group counselling intervention developed to promote wellness among adolescent girls at risk of delinquency.

Wellness evaluation among adolescents has the potential to help identify those engaging in less than ideal lifestyle behaviours. Adolescents might be reluctant to initiate communication about potentially damaging risk-taking behaviours (Stephens, 2006) and might be unwilling or unable to effectively communicate the diagnostic indicators associated with early signs of mental illness (Derouin \& Bravender, 2004). In these situations a wellness assessment tool can prove useful for those seeking to assist youth populations in establishing positive lifestyle behaviours, implement early health interventions or mitigate other health risks (Haddad, 
Table 1. The dimensions included in each of the multidimensional wellness instruments.

\begin{tabular}{l}
\hline Instrument and Model \\
\hline Wellness Evaluation of Lifestyle* ${ }^{*}$ (97- \\
131 items), founded on Wheel of \\
Wellness model
\end{tabular}

Dimensions

Spirituality; self-direction; sense of worth; sense of control; realistic beliefs; emotional awareness and coping; intellectual stimulation, problem solving and creativity; sense of humour; nutrition; exercise; selfcare; stress management; gender identity; cultural identity; work; leisure; friendship; love; total wellness; and perceived wellness.

Five Factor Wellness Inventory* (90-97 items), founded on The Indivisible Self model

Essential Self (spirituality, gender identity, cultural identity, self care), Social Self (friendship, love), Creative Self (thinking, emotions, control, work, humour), Physical Self (exercise, nutrition), Coping Self (leisure, stress management, self worth, realistic beliefs), and Total Wellness.

Perceived Wellness Survey* (36 items),
founded on the Perceived Wellness
Model

Life Assessment Questionnaire (100 items), founded on Hettler's dimensions of wellness

\begin{tabular}{ll}
\hline $\begin{array}{l}\text { Testwell* (100 items), founded on } \\
\text { Hettler's dimensions of wellness }\end{array}$ & $\begin{array}{l}\text { Social, spiritual, physical, intellectual, emotional, and } \\
\text { occupational. }\end{array}$ \\
\hline $\begin{array}{l}\text { Optimal Living Profile (135 items), } \\
\text { founded on the Total Person Concept }\end{array}$ & $\begin{array}{l}\text { Emotional, spiritual, physical, social, intellectual, and } \\
\text { environmental. }\end{array}$ \\
\hline $\begin{array}{l}\text { Wellness Inventory (120 items), } \\
\text { founded on the Wellness Energy } \\
\text { System }\end{array}$ & $\begin{array}{l}\text { Self-responsibility and love, breathing, sensing, eating, } \\
\text { moving, feeling, thinking, playing and working, } \\
\text { communication, sex, finding meaning, and } \\
\text { transcending. }\end{array}$ \\
\hline $\begin{array}{l}\text { Holistic Wellness Assessment (285 } \\
\text { items), model not described }\end{array}$ & $\begin{array}{l}\text { Self-regard, self-awareness and responsibility, } \\
\text { sustainability, relational, risk prevention, spirituality, } \\
\text { physical, health maintenance. }\end{array}$ \\
\hline $\begin{array}{l}\text { Adolescent Wellness Appraisal* (55 } \\
\text { items), model not described }\end{array}$ & $\begin{array}{l}\text { Self care and health history; health habits and } \\
\text { knowledge; safety and violence; nutrition habits; } \\
\text { drugs, alcohol and tobacco; quality of life; and both } \\
\text { school and out of school activities. }\end{array}$ \\
\hline $\begin{array}{l}\text { Juvenile Health and Wellness Survey* } \\
\text { (104 items), model not described }\end{array}$ & $\begin{array}{l}\text { General health, mental health, risk-taking behaviour, } \\
\text { socio-demographic information, and health care habits. }\end{array}$ \\
\hline $\begin{array}{l}\text { Perceived Wellness Profile }(75 \text { items) } \\
\text { model not described }\end{array}$ & $\begin{array}{l}\text { Physical activity, participation in strength and } \\
\text { stretching exercises, perceived energy level, } \\
\text { perceptions of present body weight, and smoking and } \\
\text { alcohol use among adolescents. }\end{array}$ \\
\hline $\begin{array}{l}\text { Eudaimonistic (wellbeing and humanness), role } \\
\text { performance, and adaptive health. }\end{array}$ \\
$\begin{array}{l}\text { Conception Scale* (21 items) , model not } \\
\text { described }\end{array}$ \\
\hline A
\end{tabular}

${ }^{*} \mathrm{~A}$ version of this instrument has been designed or modified specifically for administration to youth. 
Owies \& Mansour, 2009). Therefore effective measurement of wellness has application in the fields of healthcare, education, and counselling. Evaluating wellness can assist in the implementation and evaluation of wellness-related interventions among adolescents, particularly those interventions that aim to promote positive lifestyle behaviours. The purpose of this discussion is to examine the contemporary state of wellness assessment of adolescents to help inform professionals and researchers regarding instrument selection, and identify priorities for future research in this field.

\section{Wellness instruments}

A number of wellness instruments have been used in adolescent samples. These include instruments such as the WEL (Chang \& Myers, 2003; Garrett, 1999; Garrett et al., 2009; Myers \& Bechtel, 2004; Rayle, 2005; Rayle \& Myers, 2004; Smith-Adcock et al., 2008), 5F-Wel (Myers et al., 2011; Tatar \& Myers, 2010), Adolescent Wellness Appraisal (AWA) (Haddad et al., 2009; Muscari, Phillips, \& Bears, 1997), Juvenile Wellness and Health Survey (JWHS) (Pyle, McQuivey, Brassington, \& Steiner, 2003; Steiner, Erikson, Hernandez, \& Pavelski, 2002; Steiner, McQuivey, Pavelski, Pitts, \& Kraemer, 2000; Steiner, Pavelski, Pitts, \& McQuivey, 1998), Perceived Wellness Survey (PWS) (Adams, Bezner, \& Steinhardt, 1997; Schembri, Reece, \& Wade, 2006), Wellness Factor of the Laffrey Health Conception Scale (Mahon, Yarcheski, \& Yarcheski, 2005; Yarcheski, Mahon, \& Yarcheski, 2005; Yarcheski, Mahon, Yarcheski, \& Hanks, 2010), and the Personal Wellness Profile (Savage \& Holcomb, 1997). Additional measurement techniques include the use of analogue measures or scales (Bishop, Hudson, Hilton, \& Wilde, 2005; Kilgus \& Pumariega 1994; Kilgus, Pumariega, \& Rea, 2009; Kilgus, Pumariega, \& Seidel 2009), customised surveys (Ansuini, Fiddler-Woite, \& Woite, 1996; Sussman, Dent, Stacy, \& Burton, 1995), and adapted techniques such as the indicators from the Positive and Negative Affect Schedule and Satisfaction with Life Scale, and Developmental Assets Checklist (Coatsworth, Palen, Sharp, \& Ferrer-Wreder, 2006). Wellness instruments that have been used in peer-reviewed studies among adult populations, but not adolescent populations, include the Life Assessment Questionnaire (National Wellness Institute, 1983), Optimal Living Profile (Renger et al., 2000), Wellness Inventory (Travis, 1981), Holistic Wellness Assessment (Brown \& Applegate, 2012) and TestWell (National Wellness Institute, 1992).

Two common types of measures are employed to measure wellness: uni-dimensional and multidimensional measures. Uni-dimensional wellness measures employ a general overall wellness rating item such as a Likert scale or visual analogue scale. Historically, this approach has been used among healthcare populations when assessing the effects of treatments (Bishop et al., 2005; Kilgus \& Pumariega, 1994; Kilgus, Pumariega, \& Rea, 2009; Kilgus, Pumariega, \& Seidel, 2009). Uni-dimensional wellness measures encompass a single overall wellness score and are likely to have low respondent and administrator burden (due to less administration time, ease of completion, and cost). However, these measures do not allow for detailed evaluation of each dimension of wellness, and may not capture intricate changes required for evaluation of multi-faceted wellness interventions.

Some multidimensional measures report their foundation in underpinning wellness models, including the WEL (Chang \& Myers, 2003; Garrett, 1999; Garrett et al., 2009; Myers \& Bechtel, 2004; Rayle, 2005; Rayle \& Myers, 2004; Smith-Adcock et al., 2008), 5F-Wel (Myers et al., 2011; Tatar \& Myers, 2010), PWS (Adams, Bezner, Drabbs, Zambarano, \& Steinhardt, 2000; Schembri et al., 2006), and the AWA (Haddad et al., 2009; Muscari et al., 1997). A summary of the dimensions included in these instruments, and their foundational models, is presented in Table 1 (above). Other multidimensional measures do not report a foundational wellness 
model. There are some similarities and differences in dimensions between wellness instruments. The differences between instruments may allow the administrator to select an instrument that captures wellness dimensions most pertinent to their purpose for measuring wellness. However, this comes with the disadvantage that the comparisons that can be made across measures of wellness comprised of differing dimensions are limited. Multidimensional wellness measures have an advantage over uni-dimensional measures in capturing detailed information about an individual or group. While these instruments provide multidimensional assessments of wellness, they are also likely to carry a higher respondent and administrator burden due to their length and structure compared to uni-dimensional wellness measurement.

\section{Validity and reliability issues}

Perhaps the most critical issue for adolescent wellness measurement, and one common in many developing fields, is the scarcity of peer-reviewed empirical work regarding foundational validity and reliability of measurements of wellness in adolescents. Rudimentary investigations of validity and reliability of the instruments used to measure wellness in adolescents are lacking (or have produced less than ideal results) for many self-reported outcomes (Chang \& Myers, 2003; Shek et al., 2006; Steiner et al., 2000; Yarcheski et al., 2005). This is not surprising given that some instruments have been used in only a single peer-reviewed investigation of wellness among adolescents (Bishop et al., 2005; Coatsworth et al., 2006; Copeland, Nelson, \& Traughber, 2010; Papenfuss \& Beier, 1984; Shek et al., 2006; Viner et al., 2004). It is also problematic to evaluate the rigour of non peer-reviewed reports of validity and reliability that are included in user manuals for wellness instruments, such as for the WEL and 5F-Wel instruments (Myers \& Sweeney, 2004b, 2005). Therefore, it is difficult to draw firm conclusions regarding the reliability or validity of those particular instruments.

Another point for consideration is that the construct validity of wellness instruments will always be dependent on their foundational definition of wellness. This may cause debate regarding the appropriateness of some instruments for evaluating wellness while substantial variability exists across wellness definitions, models and instruments for measuring wellness. However, in the absence of a 'gold standard' definition, these debates are perhaps inevitable. For example, Coatsworth et al., (2006) considered "subjective wellbeing/life satisfaction and developmental assets" as key constructs within wellness and therefore assessed wellness with the Positive and Negative Affect Schedule, Satisfaction with Life Scale, and the Developmental Assets Checklist. Others might consider this measurement approach inappropriate if their own foundational definition of wellness is not congruent with Coatsworth's definition (Adams et al., 1997; Myers \& Sweeney, 2004a). Disagreements about what a wellness definition should include are just one of a number of barriers to consensus. Additional barriers may include the history of different priorities for assessment, religious and cultural differences, and the customary use of models or instruments within certain disciplines.

In addition to discrepancies between definitions of wellness, the latent factors being evaluated by each instrument might not always match the wellness model underpinning that instrument or might not use items with sound psychometric properties. For example, the PWS is based on the multidimensional Perceived Wellness Model. However, factor analysis of empirical data suggests the PWS does not measure the discrete dimensions in the Perceived Wellness Model, but instead represents a single latent variable (wellness) (Adams et al., 1997; Harari et al., 2005). Adams et al. (1997) concluded this did not suggest wellness is a unidimensional phenomenon, but dimensions are closely related by their perceptual nature rather than differentiated by content. Other instruments have been developed and used with 
adolescents without description of their theoretical underpinnings, and with minimal or no psychometric testing (Ansuini et al., 1996). The absence of peer-reviewed studies reporting psychometric testing for instruments used in adolescent populations is of concern and, as is common in many developing fields, highlights a priority area for future research.

The advancement of valid and reliable outcome measures to evaluate wellness in adolescents is not limited to conventional investigations to establish reliability and validity. Addressing some of the more complex issues surrounding the evaluation of change in this subjective construct (such as the response shift phenomenon (McPhail, Comans, \& Haines, 2010; McPhail \& Haines, 2010a; McPhail \& Haines, 2010b) as well as the validity of proxy reporting (McPhail, Beller, \& Haines, 2008), estimating values for minimally important difference (Hays, Farivar \& Liu, 2005) and cross-cultural adaptations of instruments (Chang \& Myers, 2003) are priorities for future research. However, perhaps the greatest overarching threat to rigorous evaluation of wellness is the lack of consensus regarding its definition (Roscoe, 2009).

A 'gold standard' definition could lead to the standardisation of a theoretical model against which wellness instruments could be validated. While there is clearly no panacea in this regard, the World Health Organization's description of wellness provides a useful starting point (Smith et al., 2006). It could be argued that variation between instruments may allow for choices which more accurately represent the purpose of the measurement. However, similarities between wellness models (Table 1) indicate that one model (or possibly an amalgamation of models) may be appropriate, and lead to harmonisation of assessment. Progress toward developing a consensus for a definition of wellness during an international meeting of experts in the field would be a worthwhile undertaking. This method has proved successful in a number of examples in the past, most notably at the International Health Conference in New York in 1946, where the Constitution of the World Health Organization was presented. This search for consensus led to the definition of health including the words "complete physical, mental and social well-being and not merely the absence of disease or infirmity" (World Health Organization, 1947).

\section{Instrument selection}

A number of factors influence professionals and researchers when they select an instrument to evaluate wellness. The most appropriate wellness measurement technique is likely to be dependent on the administrator's purpose for measuring wellness. If the purpose is to measure lifestyle wellness so that it can be enhanced, then a multidimensional measure is more likely to permit a detailed evaluation of various components of wellness. This may allow for wellness programs (whether they are intended for individual or group treatment purposes) to be tailored to those wellness dimensions with the greatest relevance. This also provides the option of the respondent being referred to an appropriate practitioner within that domain for specialised treatment. If a less detailed evaluation of wellness is required, or if an instrument with low participant and administrator burden is necessary, then a uni-dimensional question such as a Likert scale of general wellness might be more appropriate. There might also be a case for selecting a shorter multidimensional wellness measure that provides more detail than a unidimensional measure, but which is associated with less participant burden than longer multidimensional instruments. Shorter multidimensional instruments have proven to be very successful in measuring other related constructs including wellbeing (Keyes, 2002; Tennant et al., 2007) and health-related quality of life (Jenkinson \& Layte, 1997; Rabin \& Charro, 2001; Wille et al., 2010). 
When wellness in youth is assessed there might also be benefit in selecting an instrument that has been modified so as to be age appropriate. Age-adjusted instruments include modified versions of the WEL (WEL-G, at a 7th grade reading level), PWS (PWS - Youth) or 5F-Wel (5FWel-T, at a 6th grade reading level), whereas other instruments have been designed specifically for youth (AWA, JWHS). Additionally, accessibility of wellness evaluation instruments is another factor that is likely to contribute to the popularity of some instruments. Questionnaires such as the WEL and 5F-Wel can be accessed online through the host company Mind Garden Inc (Mind Garden Inc, 2010a, 2010b). However, access to some instruments with a stronger empirical foundation often comes at financial cost. At the time of writing it is not uncommon for the fee paid to copyright holders of some instruments for evaluating wellness to range between $\$ 1$ and $\$ 4$ per administration for some instruments, while other instruments do not have associated fees.

\section{Summary}

Adolescent wellness is an important indicator of future health and lifestyle habits. Instruments for evaluating wellness are particularly useful for those seeking to influence lifestyle behaviours among youth populations, including health and educational settings. There are a number of tools available to measure wellness, each with its own focus, depending on the definition or model from which it was developed. This may cause debate regarding the appropriateness of some instruments for evaluating wellness. However, in the absence of a 'gold standard' definition, substantial variability across measurement approaches is inevitable. The majority of wellness evaluation approaches used with adolescent populations have less than ideal validation. A 'gold standard' definition could lead to the standardisation of a theoretical model against which wellness instruments could be validated. Progress toward developing a consensus for a definition of wellness during an international meeting of experts in the field would be a worthwhile undertaking. The absence of peer-reviewed studies reporting psychometric testing for wellness evaluation instruments for adolescents is of concern given their growing popularity and highlights a priority area for future research in this field.

\section{Authors}

Jerome N. Rachele

Queensland University of Technology

j.rachele@qut.edu.au

Tracy L. Washington

Queensland University of Technology

Thomas F. Cuddihy

Queensland University of Technology

Faisal A. Barwais

Queensland University of Technology

Umm Al-Qura University

Steven M. McPhail

Queensland University of Technology

Centre for Functioning and Health Research, Queensland Department of Health. 


\section{Publishing Timeline}

Received 3 December 2012

Accepted 11 April 2013

Published 7 October 2013

\section{References}

Adams, T., Bezner, J., \& Steinhardt, M. (1997). The conceptualization and measurement of perceived wellness: integrating balance across and within dimensions. American Journal of Health Promotion, 11(3), 208-218. http://dx.doi.org/10.4278/0890-1171-11.3.208

Adams, T. B., Bezner, J. R., Drabbs, M. E., Zambarano, R. J., \& Steinhardt, M. A. (2000). Conceptualization and measurement of the spiritual and psychological dimensions of wellness in a college population. Journal of American College Health, 48(4), 165-173. http://dx.doi.org/10.1080/07448480009595692

Ansuini, C. G., Fiddler-Woite, J., \& Woite, R. S. (1996). The source, accuracy, and impact of initial sexuality information on lifetime wellness. Adolescence, 31(122), 283-289. PMid:8726889

Bishop, C., Hudson, V. M., Hilton, S. C., \& Wilde, C. (2005). A pilot study of the effect of inhaled buffered reduced glutathione on the clinical status of patients with cystic fibrosis. Chest, 127(1), 308317. http://dx.doi.org/10.1378/chest.127.1.308

Breslow, L. (1972). A quantitative approach to the World Health Organization definition of health: Physical, mental and social well-being. International Journal of Epidemiology, 1(4), 347-355 http://dx.doi.org/10.1093/ije/1.4.347

Brown, C., \& Applegate, B. (2012). Holistic wellness assessment for young adults: Psychometric analysis. Journal of Holistic Nursing, 30(4), 235-243. http://dx.doi.org/10.1177/0898010112453327

Chang, C. Y., \& Myers, J. E. (2003). Cultural adaptation of the Wellness Evaluation of Lifestyle: An assessment challenge. Measurement and Evaluation in Counseling and Development, 35(4), 239-250.

Choate, L. H., \& Smith, S. L. (2003). Enhancing development in 1st-year college student success courses: A holistic approach. Journal of Humanistic Counseling, Education and Development, 42(2), 178-194. http://dx.doi.org/10.1002/j.2164-490X.2003.tb00005.x

Coatsworth, J. D., Palen, L., Sharp, E. H., \& Ferrer-Wreder, L. (2006). Self-defining activities, expressive identity, and adolescent wellness. Applied Developmental Science, 10(3), 157-170. http://dx.doi.org/10.1207/s1532480xads1003_5

Copeland, E., Nelson, R. B., \& Traughber, M. (2010). Wellness dimensions relate to happiness in children and adolescents. Advances in School Mental Health Promotion, 3(4), 25-37. http://dx.doi.org/10.1080/1754730X.2010.9715689

Craigie, A. M., Lake, A. A., Kelly, S. A., Adamson, A. J., \& Mathers, J. C. (2011). Tracking of obesityrelated behaviours from childhood to adulthood: A systematic review. Maturitas, 70(3), 266-284. http://dx.doi.org/10.1016/j.maturitas.2011.08.005

Derouin, A., \& Bravender, T. (2004). Living on the edge: the current phenomenon of self-mutilation in adolescents. MCN: The American Journal of Maternal Child Nursing, 29(1), 12-18. http://dx.doi.org/10.1097/00005721-200401000-00004

Dodge, R., Daly, A. P., Huyton, J., \& Sanders, L. D. (2012). The challenge of defining well being. International Journal of Wellbeing, 2(3), 222-235. http://dx.doi.org/10.5502/ijw.v2i3.4

Dunn, H. L. (1977). What high-level wellness means. Health Values, 1(1), 9-16.

Garrett, M. T. (1999). Soaring on the wings of the eagle: Wellness of Native American high school students. Professional School Counseling, 3(1), 57-64.

Garrett, M. T., Rivera, E. T., Dixon, A. L., \& Myers, J. E. (2009). Acculturation and wellness of Native American adolescents in the United States of North America. Social Perspectives, 11(1), 41-67.

Haddad, L. G., Owies, A., \& Mansour, A. (2009). Wellness appraisal among adolescents in Jordan: a model from a developing country: a cross-sectional questionnaire survey. Health Promotion International, 24(2), 130-139. http://dx.doi.org/10.1093/heapro/dap013 
Hallal, P. C., Victora, C. G., Azevedo, M. R., \& Wells, J. C. K. (2006). Adolescent physical activity and health: A systematic review. Sports Medicine, 36(12), 1019-1030. http://dx.doi.org/10.2165/00007256200636120-00003

Harari, M. J., Waehler, C. A., \& Rogers, J. R. (2005). An empirical investigation of a theoretically based measure of perceived wellness. Journal of Counseling Psychology, 52(1), 93-103. http://dx.doi.org/10.1037/0022-0167.52.1.93

Hays, R. D., Farivar, S. S., \& Liu, H. (2005). Approaches and recommendations for estimating minimally important differences for health-related quality of life measures. COPD: Journal of Chronic Obstructive Pulmonary Disease, 2(1), 63-67. http://dx.doi.org/10.1081/COPD-200050663

Jenkinson, C., \& Layte, R. (1997). Development and testing of the UK SF-12 (short form health survey). Journal of Health Services Research and Policy, 2(1), 14. PMid:10180648

Keyes, C. L. M. (2002). The mental health continuum: From languishing to flourishing in life. Journal of Health and Behavior Research, 43, 207-222. http://dx.doi.org/10.2307/3090197

Kilgus, M. D., \& Pumariega, A. J. (1994). Experimental manipulation of cocaine craving by videotaped environmental cues. Southern Medical Journal, 87(11), 1138-1140. http://dx.doi.org/10.1097/00007611199411000-00016

Kilgus, M. D., Pumariega, A. J., \& Rea, W. S. (2009). Physiologic and cognitive changes that accompany cocaine craving in adolescents. Addictive Disorders and Their Treatment, 8(3), 128-137. http://dx.doi.org/10.1097/ADT.0b013e3181825a1b

Kilgus, M. D., Pumariega, A. J., \& Seidel, R. W. (2009). Experimental manipulation of cocaine craving in adolescents by videotaped environmental cues. Addictive Disorders and Their Treatment, 8(2), 80-87. http://dx.doi.org/10.1097/ADT.0b013e31817e41bf

Mahon, N. E., Yarcheski, A., \& Yarcheski, T. J. (2005). Happiness as related to gender and health in early adolescents. Clinical Nursing Research, 14(2), 175-190. http://dx.doi.org/10.1177/1054773804271936

McPhail, S., Beller, E., \& Haines, T. (2008). Two perspectives of proxy reporting of health-related quality of life using the Euroqol-5D, an investigation of agreement. Medical Care, 46(11), 1140-1148. http://dx.doi.org/10.1097/MLR.0b013e31817d69a6

McPhail, S., Comans, T., \& Haines, T. (2010). Evidence of disagreement between patient-perceived change and conventional longitudinal evaluation of change in health-related quality of life among older adults. Clinical Rehabilitation, 24(11), 1036-1044. http://dx.doi.org/10.1177/0269215510371422

McPhail, S., \& Haines, T. (2010a). The response shift phenomenon in clinical trials. Journal of Clinical Research Best Practices, 6(2), 1-8.

McPhail, S., \& Haines, T. (2010b). Response shift, recall bias and their effect on measuring change in health-related quality of life amongst older hospital patients. Health and Quality of Life Outcomes, 8(1), 65. http://dx.doi.org/10.1186/1477-7525-8-65

Mind Garden Inc. (2010a). Five Factor Wellness Inventory. http://www.mindgarden.com/products/ffwels.htm

Mind Garden Inc. (2010b). Wellness Evaluation of Lifestyle. http://www.mindgarden.com/products/wells.htm\#data

Muscari, M. E., Phillips, C., \& Bears, T. (1997). Health beliefs and behaviors in rural high school juniors. Pediatric Nursing, 23(4), 380-389. PMid:9282050

Myers, J. E., \& Bechtel, A. (2004). Stress, wellness, and mattering among cadets at West Point: Factors affecting a fit and healthy force. Military Medicine, 169(6), 475-482. PMid:15281680

Myers, J. E., \& Sweeney, T. J. (1999). The Five Factor Wel (WEL-J). Greensboro, NC: Authors.

Myers, J. E., \& Sweeney, T. J. (2004a). The indivisible self: An evidence-based model of wellness. The Journal of Individual Psychology, 60(3), 234-244.

Myers, J. E., \& Sweeney, T. J. (2004b). Wellness Evaluation of Lifestyle Sampler Set. Mind Garden, Inc.

Myers, J. E., \& Sweeney, T. J. (2005). Five Factor Wellness Inventory Manual and Sampler Set. Mind Garden, Inc.

Myers, J. E., Willse, J. T., \& Villalba, J. A. (2011). Promoting self-esteem in adolescents: The influence of wellness factors. Journal of Counseling and Development, 89(1), 28-36. http://dx.doi.org/10.1002/j.15566678.2011.tb00058.x 
Myers, J. E., Witmer, J. M., \& Sweeney, T. J. (2000). The wheel of wellness counseling for wellness: A holistic model for treatment planning. Journal of Counseling and Development, 78(3), 251-266. http://dx.doi.org/10.1002/j.1556-6676.2000.tb01906.x

Myers, J. E., Sweeney, T. J., \& Witmer, J. M. (1996). The Wellness Evaluation of Lifestyle. Palo Alto, CA: MindGarden.

National Wellness Institute. (1983). Life Style Assessment Questionnaire (2nd ed.). Stevens Point, WI: National Wellness Institute.

National Wellness Institute. (1992). TestWell, a Wellness Inventory. Stevens Point, WI: National Wellness Institute.

Papenfuss, R., \& Beier, B. J. (1984). Developing, implementing, and evaluating a wellness education program. Journal of School Health, 54(9), 360-362. http://dx.doi.org/10.1111/j.1746-1561.1984.tb09752.x

Power, M., Kuyken, W., Orley, J., Hermann, H., Shofield, H., Murphy, B., ... Quemada, N. (1998). The World Health Organization Quality of Life Assessment (WHOQOL): Development and general psychometric properties. Social Science and Medicine, 46(12), 1569-85. http://dx.doi.org/10.1016/S02779536(98)00009-4

Pyle, R. P., McQuivey, R. W., Brassington, G. S., \& Steiner, H. (2003). High school student athletes: Associations between intensity of participation and health factors. Clinical Pediatrics, 42(8), 697-701. http://dx.doi.org/10.1177/000992280304200805

Rabin, R., \& Charro, F. D. (2001). EQ-SD: A measure of health status from the EuroQol Group. Annals of Medicine, 33(5), 337-343. http://dx.doi.org/10.3109/07853890109002087

Rayle, A. D. (2005). Adolescent gender differences in mattering and wellness. Journal of Adolescence, 28(6), 753-763. http://dx.doi.org/10.1016/j.adolescence.2004.10.009

Rayle, A. D., \& Myers, J. E. (2004). Counseling adolescents toward wellness: The roles of ethnic identity, acculturation, and mattering. Professional School Counseling, 8(1), 81-90.

Renger, R. F., Midyett, S. J., Mas, F. G., Erin, T. E., McDermott, H. M., Papenfuss, R., ... Hewit, M. J. (2000). Optimal Living Profile: An inventory to assess health and wellness. American Journal of Health Behavior, 24(6), 403-412. http://dx.doi.org/10.5993/AJHB.24.6.1

Roscoe, L. J. (2009). Wellness: A review of theory and measurement for counselors. Journal of Counseling and Development, 87(2), 216-226. http://dx.doi.org/10.1002/j.1556-6678.2009.tb00570.x

Savage, M. P., \& Holcomb, D. R. (1997). Physical activity levels and self-reported risk-taking behavior among rural Australian and American 7th-9th grade adolescents. International Quarterly of Community Health Education, 17(4), 345-360. http://dx.doi.org/10.2190/KGPG-6C8E-TN5Y-8RCK

Schembri, A. J., Reece, J. E., \& Wade, E. (2006). Bully victimisation and psychosocial health in adolescents: Gender differences in depression, anxiety, social problems, and perceived wellness. Australian Journal of Educational Developmental Psychologist, 23(2), 17-34.

Shek, D. T. L., Siu, A. M. H., Lee, T. Y., Cheng, H., Tsang, S., Lui, J., \& Lung, D. (2006). Development and validation of a positive youth development scale in Hong Kong. International Journal of Adolescent Medicine and Health, 18(3), 547-558. PMid:17068936

Smith-Adcock, S., Webster, S., Leonard, L., \& Walker, J. (2008). Benefits of a holistic group counseling model to promote wellness for girls at risk for delinquency: An exploratory study. Journal of Humanistic Counseling, Education and Development, 47(1), 111-126. http://dx.doi.org/10.1002/j.21611939.2008.tb00051.x

Smith, B. J., Tang, K. C., \& Nutbeam, D. (2006). WHO health promotion glossary: New terms. Health Promotion International, 21(4), 340-345. http://dx.doi.org/10.1093/heapro/dal033

Steiner, H., Erickson, S. J., Hernandez, N. L., \& Pavelski, R. (2002). Coping styles as correlates of health in high school students. Journal of Adolescent Health, 30(5), 326-335. http://dx.doi.org/10.1016/S1054139X(01)00326-3

Steiner, H., McQuivey, R. W., Pavelski, R., Pitts, T., \& Kraemer, H. (2000). Adolescents and sports: Risk or benefit? Clinical Pediatrics, 39(3), 161-166. http://dx.doi.org/10.1177/000992280003900304

Steiner, H., Pavelski, R., Pitts, T., \& McQuivey, R. (1998). The juvenile wellness and health survey (JWHS76): A school based screening instrument for general and mental health in high school students. Child Psychiatry and Human Development, 29(2), 141-155. http://dx.doi.org/10.1023/A:1025088016749 
Stephens, M. B. (2006). Preventive health counseling for adolescents. American Family Physician, 74(7), 1151-1156. PMid:17039752

Sussman, S., Dent, C. W., Stacy, A. W., \& Burton, D. (1995). Psychosocial predictors of health risk factors in adolescents. Journal of Pediatric Psychology, 20(1), 91-108. http://dx.doi.org/10.1093/jpepsy/20.1.91

Tatar, M., \& Myers, J. E. (2010). Wellness of children in Israel and the United States: A preliminary examination of culture and well-being. Counselling Psychology Quarterly, 23(1), 17-33. http://dx.doi.org/10.1080/09515071003718384

Tennant, R., Hiller, L., Fishwick, R., Platt, S., Joseph, S., Weich, S., ... Stewart-Brown, S. (2007). The Warwick-Edinburgh Mental Well-being Scale (WEMWBS): Development and UK validation. Health and Quality of Life Outcomes, 5(1), 63. http://dx.doi.org/10.1186/1477-7525-5-63

Travis, J. W. (1981). The Wellness Inventory. Mill Valley, CA: Wellness Associates. PMCid:PMC426036

Trudeau, F., Laurencelle, L., \& Shephard, R. J. (2004). Tracking of physical activity from childhood to adulthood. Medicine and Science in Sport and Exercise, 36(11), 1937-1943. http://dx.doi.org/10.1249/01.MSS.0000145525.29140.3B

Viner, R., Gregorowski, A., Wine, C., Bladen, M., Fisher, D., Miller, M., El Neil, S. (2004). Outpatient rehabilitative treatment of chronic fatigue syndrome (CFS/ME). Archives of Disease in Childhood, 89(7), 615-619. http://dx.doi.org/10.1136/adc.2003.035154

Watson, J. C., \& Lemon, J. C. (2011). A profile of adolescent wellness: Implications for working with a help-seeking population. The Journal of Humanistic Counseling, 50(1), 70-83. http://dx.doi.org/10.1002/j.2161-1939.2011.tb00107.x

Wille, N., Badia, X., Bonsel, G., Burstrom, K., Cavrini, G., Devlin, N., ... \& Ravens-Sieberer, U. (2010). Development of the EQ-5D-Y: A child-friendly version of the EQ-5D. Quality of Life Research, 19(6), 875-886. http://dx.doi.org/10.1007/s11136-010-9648-y

World Health Organization. (1947). Constitution of the World Health Organization: Signed at the International Health Conference, New York, 22 July 1946. World Health Organization, Interim Commission.

Yarcheski, A., Mahon, N. E., \& Yarcheski, T. J. (2005). Psychometrics of the Laffrey Health Conception Scale for Adolescents. Journal of Nursing Measurement, 13(1), 65-76. http://dx.doi.org/10.1891/jnum.2005.13.1.65

Yarcheski, T. J., Mahon, N. E., Yarcheski, A., \& Hanks, M. M. (2010). Perceived stress and wellness in early adolescents using the Neuman Systems Model. Journal of School Nursing, 26(3), 230-237. http://dx.doi.org/10.1177/1059840509358073 